\title{
Cubic Copper Hexacyanoferrates Nanoparticles: Facile Template-Free Deposition and Electrocatalytic Sensing Towards Hydrazine
}

\author{
Xingxing Wang, ${ }^{1}$ Yun Zhang, ${ }^{1}$ Shan Jiang, ${ }^{1}$ Xiaobo Ji, ${ }^{2}$ Yong Liu, $^{1}$ and Craig E. Banks ${ }^{3}$ \\ ${ }^{1}$ College of Material Science and Engineering, Sichuan University, Chengdu, Sichuan 610064, China \\ ${ }^{2}$ State Key laboratory of Powder Metallurgy Research Institute, Central South University, Changsha 410083, China \\ ${ }^{3}$ Division of Chemistry and Environmental Science, School of Science and the Environment, Manchester Metropolitan University, \\ Manchester M1 5GD, UK
}

Correspondence should be addressed to Craig E. Banks, c.banks@mmu.ac.uk

Received 17 January 2011; Accepted 24 February 2011

Academic Editor: Kenneth I. Ozoemena

Copyright ( 2011 Xingxing Wang et al. This is an open access article distributed under the Creative Commons Attribution License, which permits unrestricted use, distribution, and reproduction in any medium, provided the original work is properly cited.

Cubic copper hexacyanoferrate (CuHCF) nanoparticles prepared via electrolytic deposition are presented with their morphology and crystalline structure characterized with SEM and XRD. The advantage of this methodology is that it allows the fabrication of uniform cubic nanoparticles with permeable structures onto the desired underlying electrode substrate. It was observed that the CuHCF film acts as a permeable membrane for cations such as $\mathrm{K}^{+}, \mathrm{Na}^{+}, \mathrm{Li}^{+}$, and $\mathrm{NH}_{4}{ }^{+}$with a selection order of $\mathrm{K}^{+}>\mathrm{Li}^{+}>\mathrm{NH}_{4}{ }^{+}>$ $\mathrm{Na}^{+}$. Furthermore, the analytical utility of these cubic-like CuHCF morphologies supported on a glassy carbon electrode was evaluated towards the electrochemical oxidation of hydrazine which was found to exhibit a linear response over the range $66 \mu \mathrm{M}$ to $17 \mathrm{mM}$ with a detection limit corresponding to $16.5 \mu \mathrm{M}$.

\section{Introduction}

There is an increasing demand for simple, inexpensive, and rapid analytical tests to detect biological and environmental compounds. Ever since the pioneering work of Neff [1] and Itaya et al. [2] using Prussian blue (PB) modified electrodes, extensive electrochemical studies on PB [3-5] and its analogue modified electrodes, such as cobalt hexacyanoferrate (CoHCF), nickel hexacyanoferrate (NiHCF), copper hexacyanoferrate (CuHCF) have been of great interest to electrochemists due to their interesting properties, especially the ability to mediate electrochemical reactions such as electrocatalyzed oxidations; for example, they can be used in biosensing for the detection of glucose $[6,7]$ and many other important analytes.

Hydrazine is widely used in various fields, for example, it is a strong reducing agent used as an oxygen scavenger for corrosion control, and it can also be employed as a starting material for different derivatives of hydrazine [8]. Moreover, hydrazine salts with methyl and dimethyl derivatives are used as rocket fuels, gas generators, and explosives [9]. It is well known that hydrazine is volatile and toxic and is easily absorbed by oral, dermal, or inhalation routes of exposure. Adverse health effects on people living near hazardous waste sites caused by hydrazine and its derivatives have been explored in detail [10], and the maximum recommended level of hydrazine is $1 \mathrm{ppm}$ in trade effluents [11]. For these reasons, it is urgently required to provide a sensitive method for the determination of hydrazine in waste water and soil.

In the present work, a feasible way to produce CuHCF films is presented via cyclic voltammetry utilizing a glassy carbon electrode as the underlying electrode substrate. Characterization of the CuHCF films via SEM indicates a uniform and compact surface covered with highly ordered cubic nanoparticles with analysis via XRD confirming that the highly ordered nano-particles have a high degree of crystallization. Note that there are many reports of utilizing metals hexacyanoferrates as electrocatalytic substrates, but 
we find only two reports which have cubic and nanomorphologies $[12,13]$. The immobilized CuHCF shows good permeability for various cations using cyclic voltammetry and exhibits electro-catalytic responses towards the sensing of hydrazine suggesting its use as a potential sensor for hydrazine with excellent analytical performances.

\section{Experimental}

All chemicals were of analytical grade from Changzheng (Chengdu, China) and were used without further purification. Electrochemical measurements were performed using an LK9805 electrochemical analyzer (Tianjin, China). A bright platinum foil served as a counterelectrode, and an $\mathrm{Ag} / \mathrm{AgCl}$ was used as reference electrode. The working electrode was a glassy carbon (GC) rod of $5 \mathrm{~mm}$ diameter encased in PTFE. Powder diffractograms were analyzed by Xray diffraction (XRD, $\mathrm{Cu} \mathrm{K}_{\alpha}$, Fine Tube, $40 \mathrm{kV}-25 \mathrm{~mA}$ ) over the $2 \theta$ range from $10^{\circ}$ to $90^{\circ}$ at a scan step of $0.06^{\circ}$. Scanning electron microscopy (SEM) was obtained on S4800 field emission scanning electron microanalyser (Hitachi, Japan).

For the preparation of the copper hexacyanoferrate modified GC electrodes, the CuHCF film was electrochemically deposited by cyclic voltammetry via cycling the glassy electrode from 0.0 to $+1.0 \mathrm{~V}$ (versus SCE) at scan rate of $50 \mathrm{mV} / \mathrm{s}$ in a fresh solution containing $0.25 \mathrm{M} \mathrm{KH}_{2} \mathrm{PO}_{3}$, $0.125 \mathrm{mM} \mathrm{CuSO}_{4}$, and $0.125 \mathrm{mMK}_{3}\left[\mathrm{Fe}(\mathrm{CN})_{6}\right]$. After 30 cycles, the GC was taken out and rinsed thoroughly with double-distilled water. After being conditioned in $0.5 \mathrm{M}$ $\mathrm{KNO}_{3}$ overnight, the electrode was ready for use.

\section{Results and Discussion}

3.1. Preparation and Characterization of CuHCF Particles on GCE. The cubic copper hexacyanoferrate (CuHCF) nano-particles were electrochemically deposited onto the surface of GC electrode by completing 30 voltammetric cycles in an aqueous solution containing $0.25 \mathrm{M} \mathrm{KH}_{2} \mathrm{PO}_{3}$, $0.125 \mathrm{mM} \mathrm{CuSO}_{4}$, and $0.125 \mathrm{mM} \mathrm{K}_{3}\left[\mathrm{Fe}(\mathrm{CN})_{6}\right]$ between 0.0 and $1.0 \mathrm{~V}$ (versus $\mathrm{Ag} / \mathrm{AgCl}$ ) at a scan rate of $50 \mathrm{mV} / \mathrm{s}$, as shown in Figure 1(a). It was found that with increasing scans both oxidation and reduction peaks increase steadily in magnitude, indicating the copper hexacyanoferrate films are deposited continuously on the GC electrode surface. Note that the peak potentials of the oxidation and reduction peak are $748 \mathrm{mV}\left(\mathrm{E}_{1}\right)$ and $704 \mathrm{mV}\left(\mathrm{E}_{2}\right)$, respectively, giving a formal potential of $726 \mathrm{mV}\left(\mathrm{E}_{m}\right)$. In addition, the redox peak potential difference $\left(\Delta E_{p}\right)$ of this copper hexacyanoferrate modified GC electrode is roughly $44 \mathrm{mV}$, suggesting these redox peaks corresponding to the following electrochemical processes:

$$
\begin{gathered}
\mathrm{Fe}(\mathrm{CN})_{6}{ }^{3-}+\mathrm{e}^{-} \longrightarrow \mathrm{Fe}(\mathrm{CN})_{6}{ }^{4-}, \\
2 \mathrm{~K}^{+}+\mathrm{Fe}(\mathrm{CN})_{6}{ }^{4-}+\mathrm{Cu}^{2+} \longrightarrow \mathrm{K}_{2} \mathrm{Cu}^{\mathrm{II}}\left[\mathrm{Fe}^{\mathrm{II}}(\mathrm{CN})_{6}\right] \\
\mathrm{K}_{2} \mathrm{Cu}^{\mathrm{II}}\left[\mathrm{Fe}^{\mathrm{II}}(\mathrm{CN})_{6}\right] \longrightarrow \mathrm{KCu}^{\mathrm{II}}\left[\mathrm{Fe}^{\mathrm{III}}(\mathrm{CN})_{6}\right]+\mathrm{K}^{+}+\mathrm{e}^{-} .
\end{gathered}
$$

It is interesting to note that sol-gel aggregation and precipitation occurs simultaneously in the process of electrochemical deposition from a colloidal solution [14]. These adverse factors will unavoidably decrease the lifetime and reproducibility of the modified electrodes between batch experiments. To overcome these problems above, the CuHCF films were subjected to an aging process before use; the modified electrodes were placed in a potassium nitrate solution for $12 \mathrm{~h} \mathrm{[9]}$.

Figure 1(b) shows an XRD pattern of the CuHCF particles as prepared by the electrochemical deposition process. The crystal structure was characterized by XRD, and a scanning rate of $0.06^{\circ} \mathrm{s}$ was applied to record the patterns in the $2 \theta$ range of $10-60^{\circ}$. Miller indexes (111), (220), (311), (400), (420), (422), (440), (600), and (620) of the diffraction planes are corresponding to the standard pattern (JCPDS 53-0084). The peak position for the main diffraction peak position agrees well with diffraction data for $\mathrm{Cu}_{1.5}\left[\mathrm{Fe}(\mathrm{CN})_{6}\right] \cdot 6 \mathrm{H}_{2} \mathrm{O}$ confirming the film composition. There are very few impurity diffraction peaks observed from CuHCF film, showing high purity and lattice structure. Moreover, the Miller indexes of the diffraction planes are all even or all odd in number, suggesting that the electrochemically deposited film has a face-centered cubic crystal structure. As shown in Figure 1(b), the relative intensity of diffraction peaks is high and the FWHM of peaks is narrow, indicating a high degree of crystallization in the film.

In addition, the morphology and grain sizes of the CuHCF nanoparticles formed on the GC electrode were examined using SEM, as shown in Figure 1(c). It is very interesting to note that those electrochemically deposited CuHCF nanoparticles at the GC electrode surface present a cubic morphology with very narrow particle size distribution with the particle size distribution, also shown, indicate that the nanoparticles have an average size of $210 \mathrm{~nm}$.

3.2. Electrochemical Behavior of the CuHCF-Modified GCE. It is well known that $\mathrm{CuHCF}$ films are potentially permeable membranes for cations such as $\mathrm{K}^{+}, \mathrm{NH}_{4}{ }^{+}, \mathrm{Li}^{+}$, and $\mathrm{Na}^{+}[15$, 16]. The electrochemical behaviors of the CuHCF-modified GCE prepared via 15 continuous cycles in $\mathrm{LiNO}_{3}, \mathrm{NaNO}_{3}$, $\mathrm{KNO}_{3}$, and $\mathrm{NH}_{4} \mathrm{NO}_{3}$ solution were explored. Figure $1(\mathrm{~d})$ presents typical cyclic voltammograms of the CuHCFmodified GC electrode in these four different supporting electrolytes. According to the limiting mobility by Stokes' law, the radius of the hydrated $\mathrm{Li}^{+}, \mathrm{Na}^{+}, \mathrm{K}^{+}$, and $\mathrm{NH}_{4}^{+}$is $2.1,1.83,1.25$, and $1.25 \AA$, respectively $[17,18]$. According to Figure $1(\mathrm{~d})$ we may determine that the transfer order is $\mathrm{K}^{+}>\mathrm{Li}^{+}>\mathrm{Na}^{+}>\mathrm{NH}_{4}^{+}$in the deposited CuHCF film. It was found that the order of $\mathrm{NH}_{4}{ }^{+}$and $\mathrm{Li}^{+}$was not as predicted $\mathrm{K}^{+}, \mathrm{NH}_{4}^{+}>\mathrm{Na}^{+}>\mathrm{Li}^{+}$, which can be a result of a strong coordination bond between $\mathrm{NH}_{3}$ and $\mathrm{Fe}^{2+}$, or $\mathrm{Cu}^{2+}$ [19], leading to partial dissolving of the CuHCF film. Note that these experiments were performed multiple times to ensure that no memory effects prevailed. The good permeability of $\mathrm{Li}^{+}$can be reasonably explained in terms of a partial dehydration of hydrated $\mathrm{Li}^{+}$that reduces the cation to an appropriate size to enter the lattice. $[20,21]$ The radii of naked ions $\mathrm{Li}^{+}, \mathrm{Na}^{+}, \mathrm{K}^{+}, \mathrm{NH}_{4}{ }^{+}$are $0.6,0.95,1.33$, and $0.99 \AA$, 


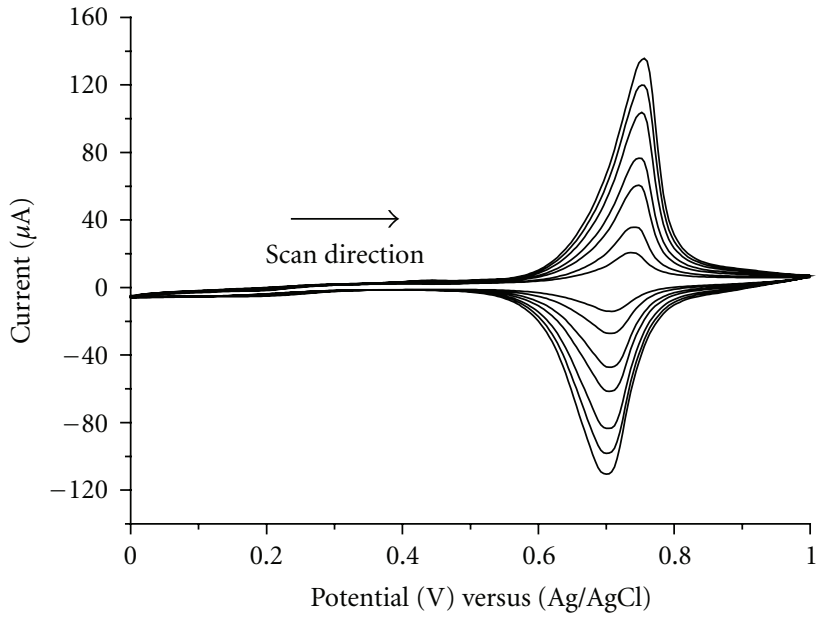

(a)

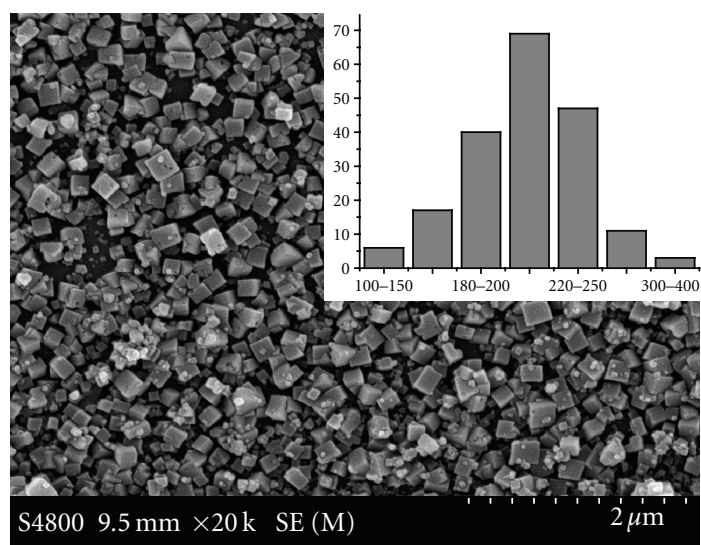

(c)

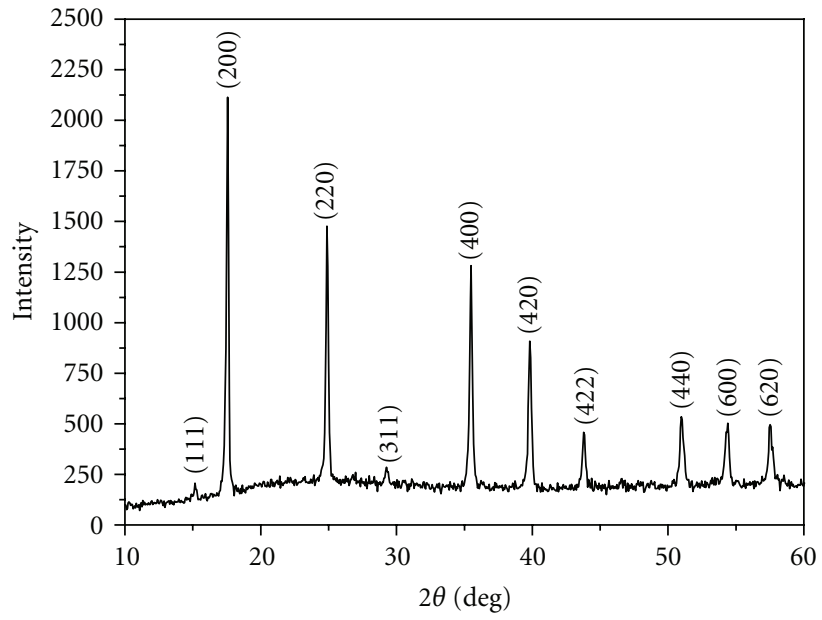

(b)

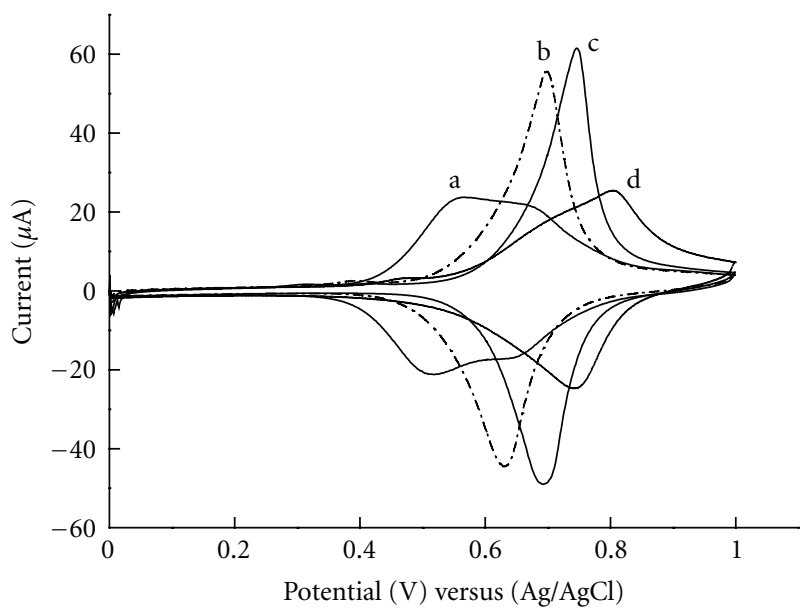

(d)

Figure 1: (a) Cyclic voltammograms (30 cycles) of CuHCF films at the glassy carbon electrode recorded in $0.25 \mathrm{M} \mathrm{KH}_{2} \mathrm{PO}_{3}+0.125 \mathrm{mM}$ $\mathrm{CuSO}_{4}+0.125 \mathrm{mM} \mathrm{K}_{3}\left[\mathrm{Fe}(\mathrm{CN})_{6}\right]$ solutions with $\mathrm{Ag} / \mathrm{AgCl}$ reference electrode. Scan rate: $50 \mathrm{mV} / \mathrm{s}$. Curves from inner to outer correspond to the 1th, 5th, 15th, 20th, 25th, and 30th cycles, respectively. (b) XRD pattern of the CuHCF film. (c) SEM image of copper hexacyanoferrates nanoparticles (CuHCFNPs). (d) Comparative cyclic voltammograms of the CuHCF-modified GCE in (A) $0.1 \mathrm{M} \mathrm{NH}_{4} \mathrm{NO}_{3}$, (B) $0.1 \mathrm{M} \mathrm{LiNO}_{3}$, (C) $0.1 \mathrm{M} \mathrm{KNO}_{3}$, and (D) $0.1 \mathrm{M} \mathrm{NaNO}_{3}$ solutions. Scan rate: $50 \mathrm{mV} / \mathrm{s}$.

and those of hydrated ions are $2.1,1.8,1.25$, and $1.25 \AA$, respectively; after complete dehydration, naked $\mathrm{Li}^{+}$has the smallest radius, which may be a prerequisite for it to be incorporated into the CuHCF lattice [12].

Figure 2(a) shows cyclic voltammetric responses of the CuHCF-modified electrode recorded in $\mathrm{KNO}_{3}$ electrolytes with $\mathrm{K}^{+}$concentrations varied from 0.01 to $0.15 \mathrm{M}$. With increasing $\mathrm{K}^{+}$concentration, the voltammetric peak potentials were shifted to more positive potentials, and the result is in good agreement with the involvement of potassium ions in the redox reaction [21]. When the peak potentials of the oxidation peak were plotted versus the logarithm of $\mathrm{K}^{+}$concentration, a straight line was obtained (insert of Figure $2(\mathrm{a}))$ with the slope $(0.398 \mathrm{~V})$ which is significantly lower than the theoretical value of $59 \mathrm{mV}$ (Nernstian behavior) which would be expected for the sole involvement of $\mathrm{K}^{+}$. A possible explanation of lower than $59 \mathrm{mV}$ slopes is due to more complex redox behavior of the CuHCF-modified electrode and/or to partial charge compensation anions from the electrolyte [22].

Figure 2(b) shows the cyclic voltammograms corresponding to the response of the CuHCF-modified GC electrode in $\mathrm{pH} 7 \mathrm{PBS}$ recorded over a range of scan rates from 15 up to $145 \mathrm{mV} / \mathrm{s}$; over this range, it is evident that the oxidation and reduction peak currents are linearly proportional to the square root of the sweep rate which suggests a diffusion-controlled rather than a surface-controlled process electrode. The linear regression equations, respectively, were

$$
\begin{array}{ll}
i_{\mathrm{pa}}(\mu A)=-18.934+8.191 \nu^{1 / 2}\left(\left(\frac{\mathrm{mV}}{\mathrm{s}}\right)^{1 / 2}\right), & r=0.9995, \\
i_{\mathrm{pc}}(\mu A)=19.126-7.232 \nu^{1 / 2}\left(\left(\frac{\mathrm{mV}}{\mathrm{s}}\right)^{1 / 2}\right), & r=0.9984 .
\end{array}
$$




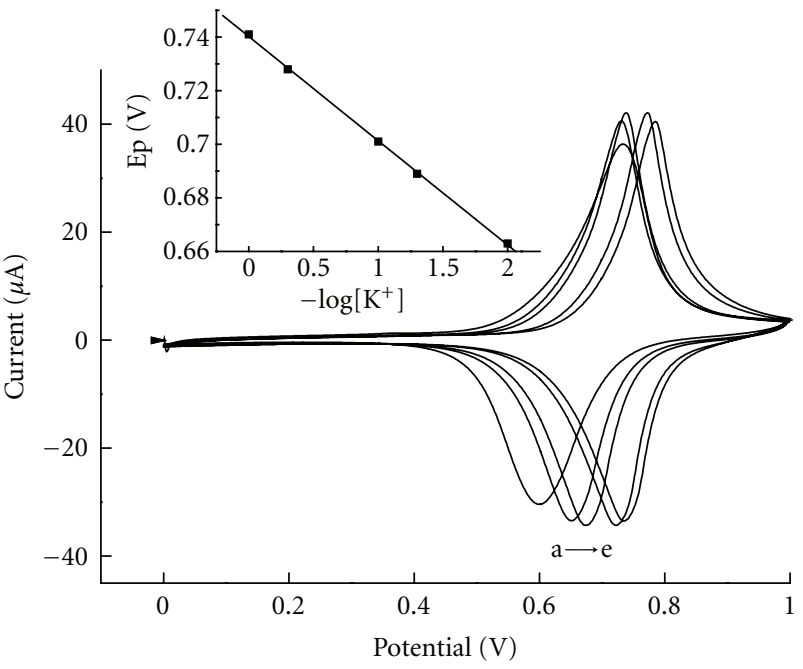

(a)

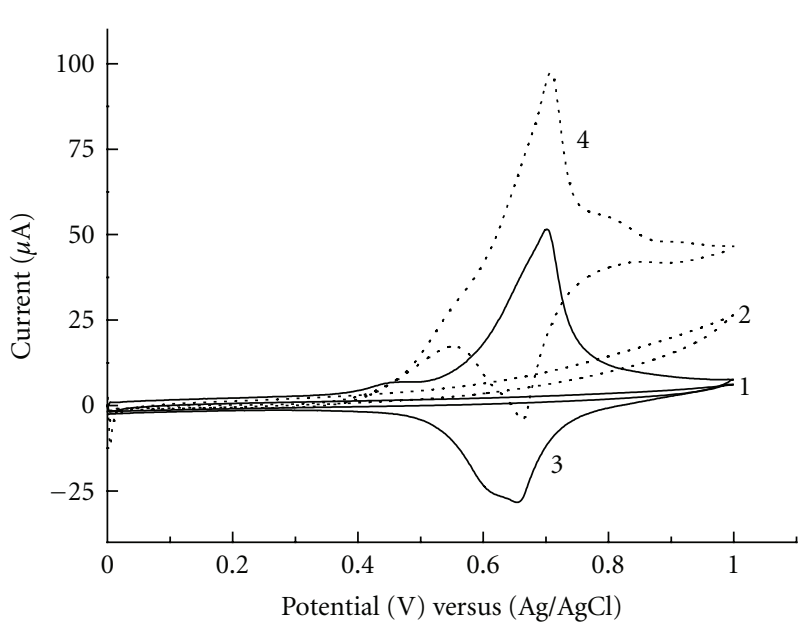

(c)

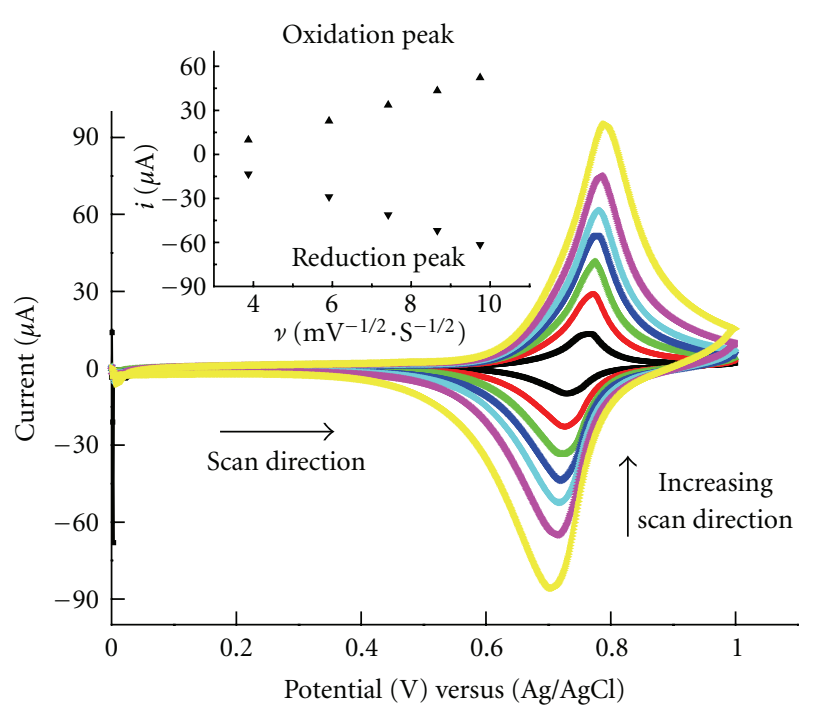

(b)

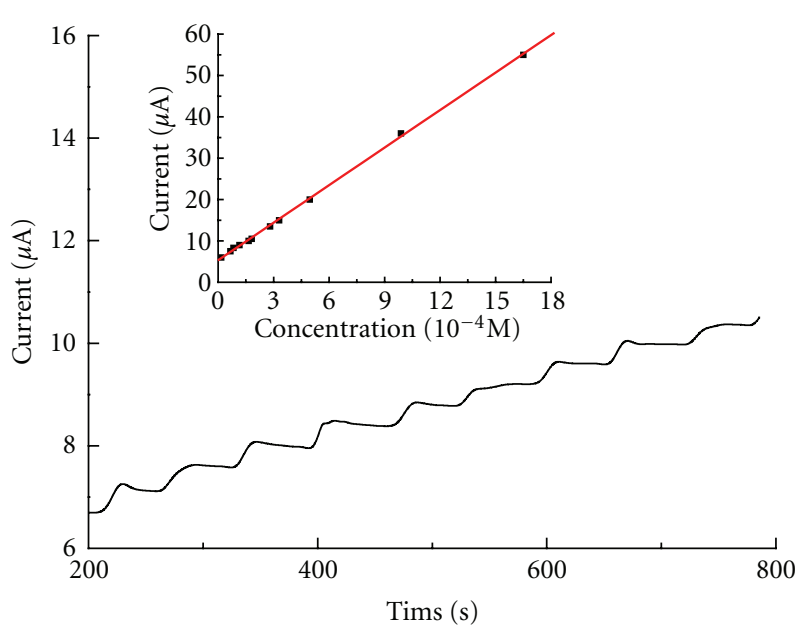

(d)

Figure 2: (a) Dependence of the cyclic voltammetric response at a CuHCF modified glass carbon paste electrode on concentrations of $\mathrm{K}^{+}$: (a) 0.01 , (b) 0.05 , (c) 0.1 , (d) 0.5 , and(e) $1 \mathrm{M}$ respectively in $\mathrm{KNO}_{3}$ buffer. Insert: plot of Ep versus - $\log \left[\mathrm{K}^{+}\right.$]. (b) Cyclic voltammetric responses of CuHCF modified electrodes at various scan rates from 15 to $145 \mathrm{mV} / \mathrm{s}$ recorded in $\mathrm{pH} 7 \mathrm{PBS}$. Inset: Plot of oxidation peak current and the reduction current for $\mathrm{CuHCF}$ modified electrodes against the square root of scan rate. (c) Cyclic voltammograms (1) at a bare glassy carbon paste, (2) bare glassy carbon paste in $66 \mu \mathrm{M}$ hydrazine in pH 7 PBS, (3) at CuHCF /GCE electrode and (4) CuHCF/GCE electrode in $66 \mu \mathrm{M}$ hydrazine. Scan rate: $50 \mathrm{mV} / \mathrm{s}$; (d) Chronoamperometric curves of the modified electrodes upon additions of hydrazine in PBS (pH 7) at + $0.72 \mathrm{~V}$. Insert: The relationship between current response of CuHCF/GCE and hydrazine concentrations.

3.3. Electrocatalytic Oxidation of Hydrazine at the CuHCFModified GCE. Next, attention was turned to evaluating the analytical performance of the CuHCF-modified electrode towards the sensing of hydrazine. The cyclic voltammetric response of the bare electrode and modified electrode in a solution of $66 \mu \mathrm{M}$ hydrazine in $\mathrm{pH} 7 \mathrm{PBS}$ is depicted in Figure 2(c), where it can be observed that the modified electrode results in an increase in oxidation peak current towards the electrochemical oxidation of hydrazine indicating an electro-catalytic nature of the CuHCF cubic nanoparticles. As is reported in literature [12], the pair of peaks observed in Figure 2(c) are likely due to the redox processes of
$\mathrm{Fe}(\mathrm{II}) / \mathrm{Fe}(\mathrm{II})$ with the potential difference between them due to the $\mathrm{K}^{+}$pairing saturation level of the iron centers.

A typical hydrodynamic amperometry (Figure 2(d)) was obtained by successively adding $0.3 \mathrm{mM}$ hydrazine into continuously agitated pH 7 PBS solution. The CuCHF/GCE exhibited well-defined current responses with the response of the electrode being very fast in reaching a dynamic equilibrium upon each addition of the sample solution, with a response time of less than 4 seconds. With the addition of hydrazine, the current increased in a stepwise fashion with the insert of Figure 2(d) depicting the calibration graph for hydrazine at the CuCHF/GCE. The electrode response is 
found to be linear towards hydrazine over the concentration range from $66 \mu \mathrm{M}$ to $16.7 \mathrm{mM}$. The detection limit was found, based on 3-sigma, to correspond to $16 \mu \mathrm{M}(n=4)$ which is superior to previous literature reports such as [23, 24] utilizing metal hexacyanoferrate films and is analytically useful towards potential applications where hydrazine needs to be monitored. The difference in analytical performance might likely be due to the cubic morphology of the $\mathrm{CuCHF}$ on the GC electrode where other reports utilize a thin film $[23,24]$.

\section{Conclusions}

A simple method was used to construct a CuHCF/GCE electrode which exhibited an analytically useful performance towards the sensing of hydrazine. The modified electrode, when combined with separation methods such as flow injection and liquid chromatography, can be used for industry, environmental, and biological samples for microquantitative determination of hydrazine content; we are currently exploring the $\mathrm{CuHCF}$ cubic morphologies on other electrode substrates and into real sample analysis.

\section{References}

[1] V. D. Neff, "Electrochemical oxidation and reduction of thin films of prussian blue," Journal of the Electrochemical Society, vol. 125, pp. 886-887, 1978.

[2] K. Itaya, T. Ataka, and S. Toshima, "Electrochemical preparation of a prussian blue analogue: iron-ruthenium cyanide," Journal of the American Chemical Society, vol. 104, no. 13, pp. 3751-3752, 1982.

[3] P. A. Christensen, A. Hamnett, and S. J. Higgins, "A study of electrochemically grown prussian blue films using Fouriertransform infra-red spectroscopy," Journal of the Chemical Society, Dalton Transactions, no. 7, pp. 2233-2238, 1990.

[4] K. Ogura, M. Nakayama, and K. Nakaoka, "Electrochemical quartz crystal microbalance and in situ infrared spectroscopic studies on the redox reaction of Prussian blue," Journal of Electroanalytical Chemistry, vol. 474, no. 2, pp. 101-106, 1999.

[5] A. Dostal, B. Meyer, F. Scholz et al., "Electrochemical study of microcrystalline solid Prussian blue particles mechanically attached to graphite and gold electrodes: electrochemically induced lattice reconstruction," Journal of Physical Chemistry, vol. 99, no. 7, pp. 2096-2103, 1995.

[6] J. Wang, X. Zhang, and M. Prakash, "Glucose microsensors based on carbon paste enzyme electrodes modified with cupric hexacyanoferrate," Analytica Chimica Acta, vol. 395, no. 1-2, pp. 11-16, 1999.

[7] J. Zhou and E. Wang, "Sensitive amperometric detection of glucose by reversed phase liquid chromatography at a Prussian Blue chemically modified electrode of novel construct," Journal of Electroanalytical Chemistry, vol. 331, no. 1-2, pp. 10291043, 1992.

[8] H. W. Schessl, "Hydrazine and Its Derivatives," in Encyclopedia of Chemical Technology, K. Othmer, Ed., vol. 13, p. 560, 1995.

[9] A. Abbaspour and M. A. Kamyabi, "Electrocatalytic oxidation of hydrazine on a carbon paste electrode modified by hybrid hexacyanoferrates of copper and cobalt films," Journal of Electroanalytical Chemistry, vol. 576, no. 1, pp. 73-83, 2005.
[10] J. W. McCargar and V. D. Neff, "Thermodynamics of mixedvalence intercalation reactions: the electrochemical reduction of Prussian blue," Journal of Physical Chemistry, vol. 92, no. 12, pp. 3598-3604, 1988.

[11] K. Itaya, T. Ataka, and S. Toshima, "Spectroelectrochemistry and electrochemical preparation method of Prussian Blue modified electrodes," Journal of the American Chemical Society, vol. 104, no. 18, pp. 4767-4772, 1982.

[12] S. Ayrault, B. Jimenez, E. Garnier, M. Fedoroff, D. J. Jones, and C. Loos-Neskovic, "Sorption mechanisms of cesium on $\mathrm{Cu}_{2}^{\mathrm{II}} \mathrm{Fe}^{\mathrm{II}}(\mathrm{CN})_{6}$ and $\mathrm{Cu}_{3}^{\mathrm{II}}\left[\mathrm{Fe}^{\mathrm{III}}(\mathrm{CN})_{6}\right]_{2}$ hexacyanoferrates and their relation to the crystalline structure," Journal of Solid State Chemistry, vol. 141, no. 2, pp. 475-485, 1998.

[13] S. Ayrault, C. Loos-Neskovic, M. Fedoroff, E. Garnier, and D. J. Jones, "Compositions and structures of copper hexacyanoferrates(II) and (III): experimental results," Talanta, vol. 42, no. 11, pp. 1581-1593, 1995.

[14] I. V. Tananaev, G. B. Seifer, Y. Y. Kharitonov, V. G. Kuznetsov, and A. P. Korolkov, The Chemistry of Ferrocyanides, 1971.

[15] Y. Wang, G. Zhu, and E. Wang, "Electrochemical quartz crystal microbalance study for vanadium hexacyanoferrates: monitoring of film growth and ion effects during redox reactions," Journal of Electroanalytical Chemistry, vol. 430, no. 1-2, pp. 127-132, 1997.

[16] M. A. Malik, G. Horanyi, P. J. Kulesza et al., "Microgravimetric monitoring of transport of cations during redox reactions of indium(III) hexacyanoferrate(III,II) Radiotracer evidence for the flux of anions in the film," Journal of Electroanalytical Chemistry, vol. 452, no. 1, pp. 57-62, 1998.

[17] K. Itaya, T. Ataka, and S. Toshima, "Electrochemical preparation of a prussian blue analogue: iron-ruthenium cyanide," Journal of the American Chemical Society, vol. 104, no. 13, pp. 3751-3752, 1982.

[18] D. Shaojun and L. Fengbin, "Researches on chemically modified electrodes. Part XV. Preparation and electrochromism of the vanadium hexacyanoferrate film modified electrode," Journal of Electroanalytical Chemistry, vol. 210, no. 1, pp. 3144, 1986.

[19] T. Y. Sun, J. N. Xu, and G. Z. Cheng, Inorganic Chemistry, High Education Press, Beijing, China, 2004.

[20] P. J. Kulesza, M. A. Malik, M. Berrettoni et al., "Electrochemical charging, countercation accommodation, and spectrochemical identity of microcrystalline solid cobalt hexacyanoferrate," Journal of Physical Chemistry B, vol. 102, no. 11, pp. 1870-1876, 1998.

[21] X. Cui, L. Hong, and X. Lin, "Electrochemical preparation, characterization and application of electrodes modified with hybrid hexacyanoferrates of copper and cobalt," Journal of Electroanalytical Chemistry, vol. 526, no. 1-2, pp. 115-124, 2002.

[22] P. Wang, Y. Yuan, X. Jing, and G. Zhu, "Amperometric determination of thiosulfate at a surface-renewable nickel(II) hexacyanoferrate-modified carbon ceramic electrode," Talanta, vol. 53, no. 4, pp. 863-869, 2001.

[23] R. E. Sabzi, E. Minaie, K. Farhadi, and M. M. Golzan, "Nile Blue-hexacyanoferrate carbon paste modified electrode as an amperometric sensor for determination of hydrazine," Turkish Journal of Chemistry, vol. 34, no. 6, pp. 901-910, 2010.

[24] A. Abbaspour and M. A. Kamyabi, "Electrocatalytic oxidation of hydrazine on a carbon paste electrode modified by hybrid hexacyanoferrates of copper and cobalt films," Journal of Electroanalytical Chemistry, vol. 576, no. 1, pp. 73-83, 2005. 


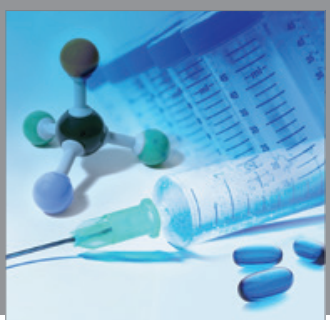

International Journal of

Medicinal Chemistry

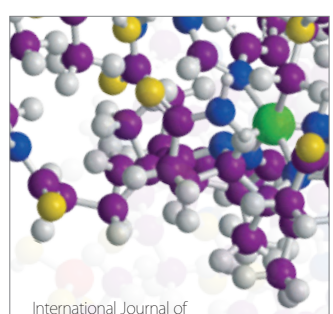

Carbohydrate Chemistry

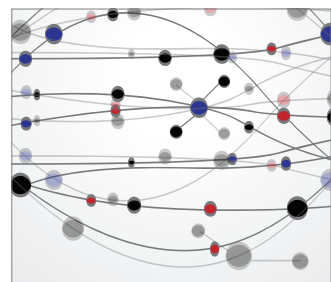

The Scientific World Journal
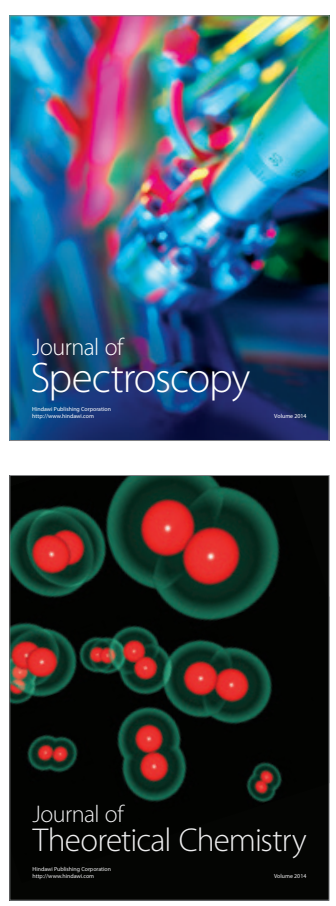
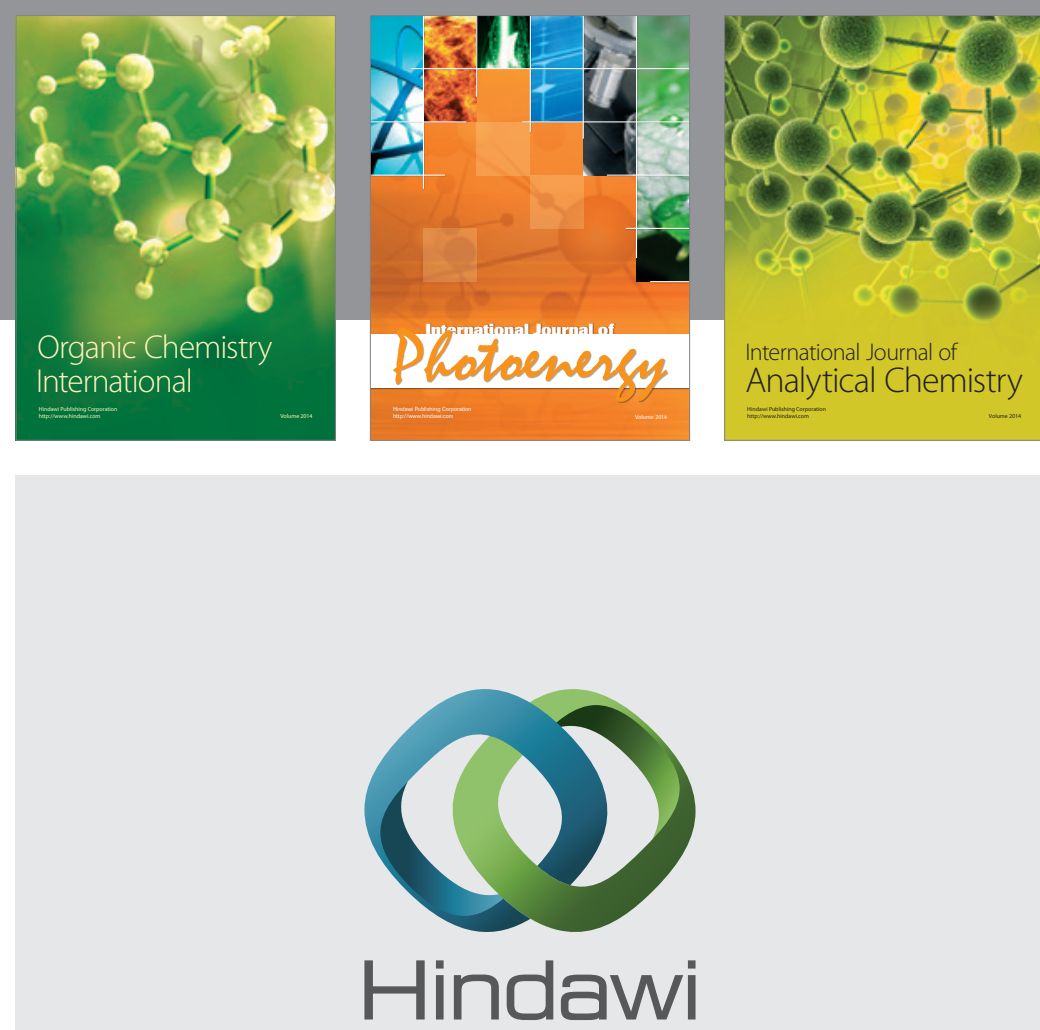

Submit your manuscripts at

http://www.hindawi.com
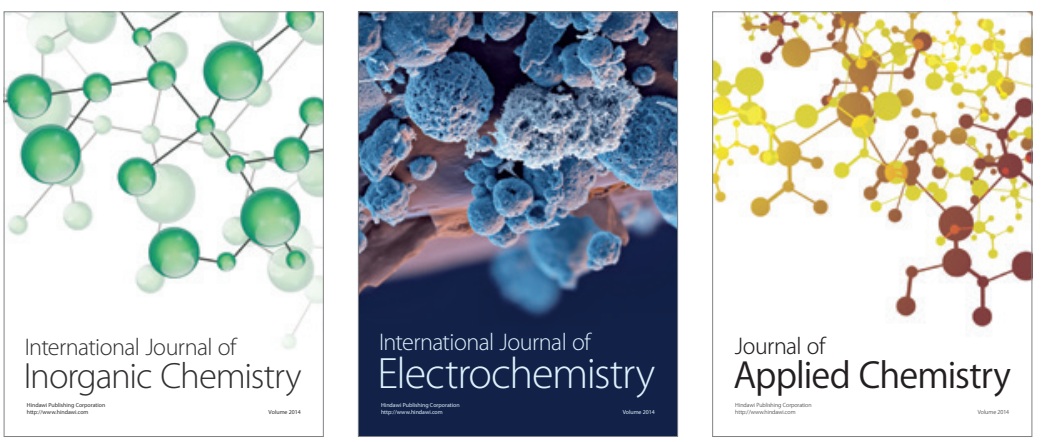

Journal of

Applied Chemistry
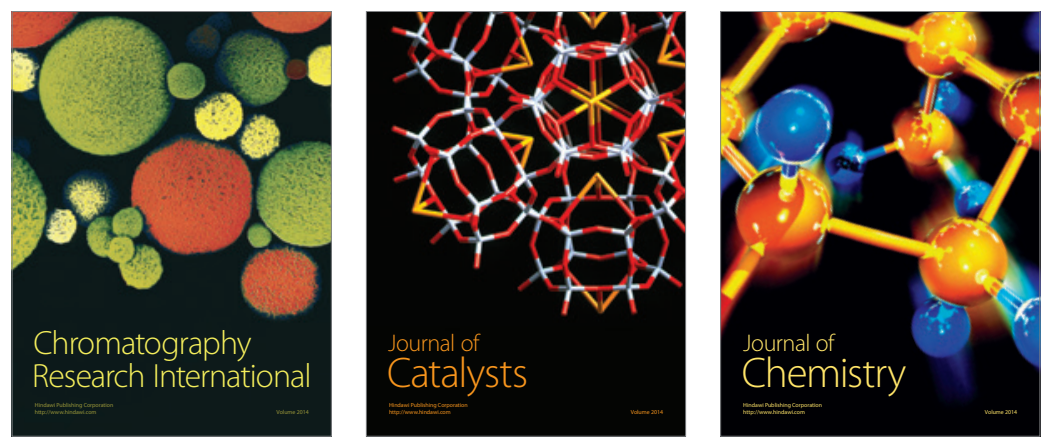
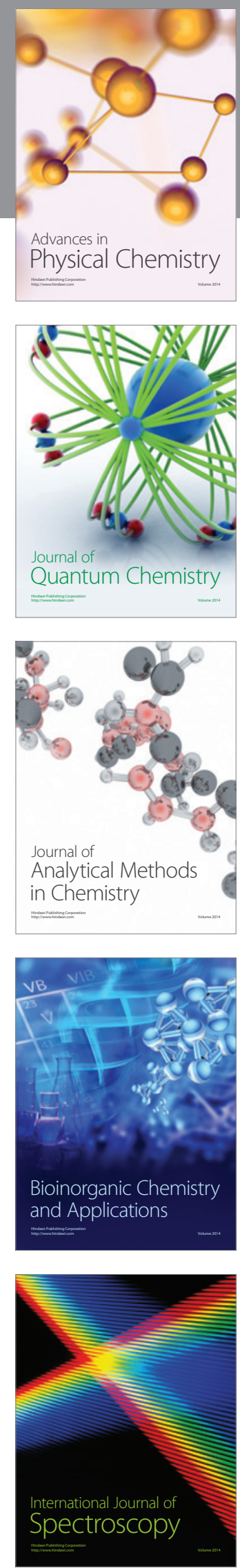